\title{
STRATEGI PEMASARAN TERHADAP IMPULSE BUYING (Penelitian Pada Konsumen Sinar Terang Bersaudara)
}

\author{
MARKETING STRATEGY AGAINST IMPULSE BUYING \\ (Research on the Consumers of the Bright Rays of the Brothers)
}

\author{
Nurjannatul Hasanah ${ }^{1}$ Arifudin ${ }^{2}$
}

Program Studi Manajemen, Fakultas Ekonomi Universitas Borneo Tarakan nurjannatulh@yahoo.com

\begin{abstract}
Abstrak: Penelitian ini bertujuan untuk mengetahui pengaruh suasana toko, potongan harga, dan tenaga penjual terhadap pembelian impulsif (penelitian pada konsumen di Supermarket Sinar Terang Bersaudara). Penelitian ini menggunakan pendekatan kuantitatif dengan metode survei. Metode pengambilan sampel yang digunakan adalah teknik nonprobability sampling dengan menggunakan sampel purposive sampling. Sampel dalam penelitian ini adalah masyarakat Kota Tarakan yang pernah berbelanja di toko Terang Sinar Bersaudara dengan jumlah sampel 100 orang. Metode analisis yang digunakan adalah analisis regresi dengan bantuan program SPSS versi 22. Hasil penelitian ini menunjukkan bahwa variabel suasana berpengaruh positif dan signifikan terhadap pembelian impulsif. Sedangkan variabel diskon dan tenaga penjual tidak berpengaruh dan signifikan terhadap pembelian impulsif.
\end{abstract}

Kata kunci: Toko Atmosfer, Pembelian Impulsif, Harga Diskon, Tenaga Penjual

Abstract: The objective of this research wastodetermine thein fluence of the atmosphere stores, discounted prices, and salesperson agains the purchase of impulsivity research on costumer in Supermarket at Sinar Terang Bersaudara). This research used quantitative approaches with survey methods. Sampling method used is the nonprobability sampling technique using a purposive sampling sample. The samples in this research were the people of Tarakan City who had shopped at the Terang Sinar Bersaudara store with a sample of 100 people. The analytical method used is the analysis of regression with the help of SPSS program version 22. The results of this study showed that the atmosphere variable took a positive and significant effect on the purchase of impulsivity. 
While the discount variables and sales person have no effect and significant to the purchase of impulsivity.

Keywords: The Atmosphere Stores, The Purchase Of Impulsivity, Discounted Prices, Sales Person

\section{PENDAHULUAN}

Bisnis ritel atau eceran di Indonesia mengalami perkembangan cukup pesat, ditandai dengan semakin banyaknya bisnis ritel tradisional yang mulai membenahi diri menjadi bisnis ritel modern maupun munculnya bisnis ritel modern yang baru. Usaha ritelatau eceran (retailing) dapat dipahami sebagai semua kegiatan yang terlibat dalampenjualanbarangataujasasecara langsung kepada konsumen akhir untuk penggunaan pribadi dan bukan penggunaan bisnis (Utami,2006).

Sejalan dengan perkembangan kebutuhan dan pola hidup masyarakat yang semakin menginginkan kenyamanan belanja, kepastian harga, dan keanekaragaman barang kebutuhan dalam satu toko, pelanggan menuntut pengusaha ritel dan toko untuk meningkatkan baik pengelolaan, penampilan toko, maupun cara pelayanan. Oleh karena itu, belakangan ini dikenal ritel modern dengan cara pengelolaan secara profesional untuk jaringan toko mencakup supermarket. Supermarket adalah menjual barangbarang kebutuhan sekunder seperti pakaian, accessories, dan barangbarang perlengkpan lainnya (Foster, 2008).

Meningkatnya jumlah bisnis ritel modern menimbulkan persainganyangketat antara pemilik bisnis ritel di Indonesia. Hal tersebut menuntut para pemilik gerai ritel untuk mempunyai strategi pemasaran agar dapat bertahan ditengah persaingan usaha ritel yang cukup ketat sehingga tujuanperusahaan yaitu peningkatan keuntungan dapat tercapai. Semakin maraknya ritel modern tentu saja menimbulkan persaingan sesama ritel modern tersebut. Mulai dari persaingan harga, cara pelayanan dan penawaran keuntungan bagi konsumen. Maraknya ritel memudahkan konsumen untuk memilih ritel yang disukai dan cocok dengan keinginan konsumen sehingga konsumen dengan mudah bisa beganti ritel yang dikunjungi atau tetap loyal dengan satu ritel karena sudah merasa cocok.

Menyikapipersainganindustrir itel yang semakin kompetitif maka pengusaha ritel harus memperhatikan atmosfer toko dan promosi penjualan serta pelayanan yang mampu menarik konsumen (Aini et al., 2016). Penataan 
Suasana toko dapat menimbulkan beberapa manfaat seperti membantu mengarahkan perhatian konsumen (dalam hal ini erat kaitannya dengan memperbesar ketertarikan mereka), menggerakkan reaksi dan emosi konsumen, dan memerhatikan konsumen seperti apa yang disasar agar bisa menentukan positioning sebuah toko (Santosa, 2014 dalam Gumilang dan Nurcahya 2016). Berkaitan dengan atmosfer toko, Youn \& Faber (2000) menemukan bahwa atmosfer suatutoko memperbesar kemungkinan terjadinya perilaku impulsif. Penelitian Soars (2009) menemukan adanyapengaruhpositif atmosfer gerai terhadap pembelian impulsif. Hasil studi Crawford dan Melewar (2003) menunjukkan pengaruh atmosfir toko terhadap pembelian impulsif.

Selain atmosfer toko, adanya strategi harga yang ditetapkan perusahaan seperti adanya potongan harga bisa menyebabkan produk tersebut menjadi produk impulse. Strategi yang dapat dilakukan pemilik ritel modern untuk menarik konsumen adalah dengan pemberian discount (potongan harga). Harga diskon adalah strategi promosi penjualan yang paling banyak digunakan baik online maupun offline (Chen et al., 2012 dalam Gumilang dan Nurcahya,2016). les person merupakan salah satu faktor untuk mempengaruhi pembelian yang tidak direncanakan. Sales person memfasilitasi konsumen saatberbelanja di gerai. Dengan memberikan informasi tentang produk atau alternatif yang mungkin berbeda dapat mendorong konsumen untuk melakukan pembelian. Oleh sebab itu peritel harus dapat mengontrol sales person sebaik mungkin untuk memberikan pelayanan terbaik bagi konsumen agar dapat meningkatkan pembelian impulsif konsumen. Sales person harus mampu berkomunikasi yang baik kepada konsumen dan juga menguasai infomasi tentang produk yang ditawarkan.

Berdasarkan hasil wawancara terhadap 20 remaja usia 19 - 21 tahun juga menunjukan bahwa dari 20 remaja di daerah yang diwawancarai memiliki perilaku pembelian dadakan atau impulsif seperti yang terlihat pada table 1.1 berikut : 
Tabel 1.1

Hasil Wawancara Mengenai Pembelian Impulsif

\begin{tabular}{|l|c|c|c|}
\hline \multicolumn{1}{|c|}{ Pernyataan } & Setuju & $\begin{array}{c}\text { Tiak } \\
\text { Setuju }\end{array}$ & Total \\
\hline Saya suka berberlanja tanpa direncanakan di STB. & $\begin{array}{c}17 \\
85 \%\end{array}$ & $\begin{array}{c}3 \\
15 \%\end{array}$ & 20 \\
\hline $\begin{array}{l}\text { Walaupun mungkin tidak sesuai dengan kebutuhan, saya } \\
\text { akan tetap membeli produk tersebut. }\end{array}$ & $\begin{array}{c}11 \\
55 \%\end{array}$ & $\begin{array}{c}9 \\
45 \%\end{array}$ & 20 \\
\hline $\begin{array}{l}\text { Saya membeli produk dengan model terbaru ketika } \\
\text { melihatnya }\end{array}$ & $\begin{array}{c}13 \\
65\end{array}$ & $\begin{array}{c}7 \\
45\end{array}$ & 20 \\
\hline Jumlah & $\begin{array}{c}41 \\
68\end{array}$ & $\begin{array}{c}19 \\
32 \%\end{array}$ & $\begin{array}{c}60 \\
100\end{array}$ \\
\hline
\end{tabular}

Sumber : Data primer diolah,(2018)

Tabel 1.1 menunjukan bahwa 13,7 persen jawaban dari 20 para responden atas ketiga buah pernyataan tersebut adalah setuju, sehingga dapat dinyatakan bahwa respondencenderung memiliki perilaku pembelianmendadak atau impulsif di Supermarket Sinar Terang Bersaudara.

Pembelian impulsif dapat terjadi ketika individu mengalami perasaan terdesak secara tiba-tiba yang tidak dapat dilawan. Kecenderungan untuk membeli secara spontan ini umumnya dapat menghasilkan pembelian ketika konsumen percaya bahwa tindakan tersebut adalah hal yang wajar (Solomon, 2007 dalam Gumilang dan Nurcahya, 2016).

Objek penelitian di Toko Sinar Terang Bersaudara. STB merupakan format ritel paling besar tentunya perlu menerapkan strategi yang baik untuk mempertahankan bisnisnya terutama pada masa seperti ini. Gerai ritel modern perlu menerapkan strategiyaitu melalui pemahaman padapemasaranyang berorientasi pada pasar yang mensyaratkan pemahaman yang baik mengenai perilaku konsumen.

Hasil studi Tendai dan Crispen (2009) menunjukkan bahwa faktor- faktor yang berkaitan dengan atmosfir toko seperti kepadatan pelanggan, bau wangi dalam toko, musik latar, dan ventilasi tidak berpengaruh signifikan terhadap pembelian impulsif.

Berdasarkan uraian dan latar belakang masalah dalam penelitian ini, maka dapat ditarik rumusan masalah sebagai berikut:
a. Apakah Atmosfer Toko berpengaruh 
pembelian impulsif?

\begin{tabular}{|c|c|}
\hline $\begin{array}{l}\text { ApakahHarga } \\
\text { berpengaruh } \\
\text { pembelian impulsif? }\end{array}$ & $\begin{array}{l}\text { Diskon } \\
\text { terhadap }\end{array}$ \\
\hline $\begin{array}{l}\text { Apakah Sales } \\
\text { berpengaruh } \\
\text { pembelianimpulsif? }\end{array}$ & $\begin{array}{l}\text { Person } \\
\text { terhadap }\end{array}$ \\
\hline
\end{tabular}

\section{TINJAUAN PUSTAKA}

\section{Atmosfer Toko}

Menurut Utami (2010), atmosfer toko berarti rancangan lingkungan melaluikomunikasi visual, pencahayaan, warna, musik, dan wangi-wangian untuk merancang respon emosional dan perseptual pelanggan dan untuk mempengaruhi pelanggan dalam membeli barang. Atmosfer toko adalah langkah untuk memanipulasi desain bangunan, ruang interior, tata ruang, bau, warna, bentuk, suara dan menciptakan suasana terencana yang mampu menarik konsumen untuk membeli (Aini et al., 2016).

Indikator-indikator penting yang menjadi pengukuran dalam atmosfer tokoadalah,(BermandanEvans, 1992):
1) Tempat parkir
2) Pencahayaan toko
3) Kondisi ruangan nyaman
4) Penataan display produk
5) Alunan musik
6) Pemasangan tanda-tanda

\section{Potongan Harga}

Diskon atau potongan harga merupakan salah satu bentuk dari promosi penjualan yang sering diterapkan oleh pemasar yang lebih ditujukan kepada konsumen akhir. Konsumen menyukai diskon karena konsumen mendapat penguragan kerugian dari potongn harga langsung dari suatu produk (Ben Lowe dalam dalam Aterrine et al., 2011).

Indikator-indikator penting yang menjadi pengukuran dalam harga diskon adalah, (Belch Belch, 2009, Kotler dam Amstrong 2001) :

1) Dapat memicu konsumen untuk membeli dalam jumlah yangbanyak

2) Diskonmusiman

3) Hemat

4) Murah

\section{Sales Person}

Tenaga penjualan atau sering disebut sales person adalah perpanjangan tangan perusahaan untuk menyampaikan manfaat produk ke calon pelanggan. Pramuniaga merupakan aspek yang penting dalam pelayanan toko. Pramuniaga merupakan penghubung antara pemilik took dengan pelanggan. Pramuniaga sebagai salah satu ujung tombak yang selalu langsung berhubungan dengan konsumen menjadi salah satu sentral bagi standar pelayanan mini market. Selama melayani para konsumen, para pramuniaga yang dipekerjakan oleh mini market menjadi sorotan oleh konsumen 
yang datang dan dilayani (Nisaq, 2017).

Indikator-indikator penting yang menjadi pengukuran dalam sales person adalah, (Hidayat dan Astuti, 2017):

1) Pengetahuan InformasiProduk

2) KemampuanMenyampaikan

3) KemampuanMelayani

4) Kepercayaan pada salesperson

\section{Pembelian Impulsif}

Pembelian Impulsif (pembeli tidak terencana) merupakan perilaku pembelian tidak terencana pada konsumen yang dikarakteristikkan dengan pengambilan keputusan yang relatif cepat dan pengaruh subyektif dalam pemenuhan kebutuhan. Hal ini biasa terjadi pada produk-produk low involment yang selalu tidak memerlukan pertimbangan yang rumit untuk membelinya. Produk lowinvolvement adalah produk yang dibeli secara rutin dengan pemikiran dan usaha yang minimum, karena bukan merupakan suatu hal yang vital dan juga tidak memberikan pengaruh yang besar terhadap gaya hidup konsumen (Sari, 2017). Pembelian tidak terencana adalah pilihan yang dibuat untuk melakukan pembelian dikarenakan emosi yang timbul karena suatu benda atau keputusan pembelian yang dibuat secara spontan setelah melihat barang (Aini et al.,2016).
Indikator-indikator penting yang menjadi pengukuran dalam pembelian impulsif adalah, (Rook dan Fisher 1995):

1) SpontanitasPembelian.

2) Pure Impulsive: terjadi setelah melihat barang.

3) Reminder Impulsive: terjadi setelah ketika mengingat atau melihatiklan.

4) Membeli karena ada penawaran menarik.

5) Tidak dapat menahankeinginan

\section{METODE PENELITIAN}

Penelitian ini menggunakan pendekatan kuantitatif dengan metode survei. Lokasi penelitian ini dilakukan di Wilayah Kota tarakan. Objek dalam penelitian ini adalah Toko SinarTerang Bersaudara (STB) yang berlamat di Jalan Kusuma Bangsa (Boom Panjang) Kelurahan Pamusian Kota Tarakan. Subjek dalam penelitian ini adalah konsumen Toko Sinar Terang Bersaudara di Kota Tarakan yang pernah berbelanja minimal lebih dari satukali.

Populasi pada penelitian ini adalah masyarakat yang pernah melakukan kegiatan belanja di Toko Sinar Terang Bersaudara (Boom Panjang) yang berada di Kota Tarakan dengan jumlah populasi yang tidak diketahui. Penentuan sampel dalam penelitian ini diambil dengan menggunakan teknik nonprobability sampling, dengan 
metode digunakan purposive sampling dengan kriteria konsumen yang pernah berbelanja di Sinar Terang Bersaudara lebih dari satu kali.

Pengambilan sampel sebanyak 5 x 19 indikator $=95$ dibulatkan menjadi 100 sampel. Jadi, sampel yang digunakan adalah sebanyak 100 responden dengan menggunakan rumus Hair et al., (1998) dalam penelitian Musyaffaq (2017).

Teknik pengumpulan data yang digunakan adalah dengan menggunakan kuesioner (angket), wawancara, dan studi pustaka (Sugiono, 2017). Skala pengukuran yang digunakan adalah menggunakan skala (likert). Dengan skala likert, maka variabel yang akan diukur dijabarkan menjadi indikator variabel. Jawaban setiap item instrumen yang menggunakan skala Likert mempunyai gradasi dari sangat positif sampai sangat negatif dan pemberian skor tiap jawaban dapat diklasifikasikan sebagai berikut (Sugiono, 2017):

1. Sangat Setuju (SS) dengan nilai5

2. Setuju (S) dengan nilai 4

3. Ragu-ragu ( $R G)$ dengan nilai3

4. Tidak Setuju (TS) dengan nilai2

5. Sangat Tidak Setuju (STS) dengan nilai1.

\section{Metode Analisis Data}

Dalam menganalisa data peneliti menggunakan metode analisis yang terdiri dari:
Uji Validitas, pengujian validitas dilakukandenganmembandingkannila $\mathrm{i} r$ hitung dan $r_{\text {tabeldengan tingkat }}$ signifikan sebesar 5\% dari degree of freedom $(\mathrm{df})=\mathrm{n} 2 . \quad$ Jika $\quad \mathrm{r}_{\text {hitung }}>\mathrm{r}_{\text {tabel }}$ maka pertanyaan atau indikator tersebut dinyatakan valid (Ghozali, 2018).

Hasil uji validitas menunjukkan bahwa nilai person correlation ( $\mathrm{r}$ hitung) yang terendah sebesar 0,520 dan yang tertinggi sebesar 0,837 . Hasil tersebut>dari nilai thitung sebesar 0.1966. dapat disimpulkan bahwa keempat variabel tersebut dinyatakan valid.

Uji Reliabilitas, pengukuran reliabilitas dilakukan dengan cara one shot atau pengukuran sekali saja dengan alat bantu SPSS uji statistik Cronbach Alpha $(\alpha)$. Suatu variabel dikatakan reliabel jika memberikan nilai Cronbach Alpha > 0,60 (Sujarweni, 2015). Berdasarkan hasil uji reliabilitas, diperoleh nilai cronbach's alpha dari keempat variabel sebesar $0,665,0,787,0,834$, 0,793. Hasil ini lebih besar dari syarat nilai cronbach's alpha sebesar 0,60. Dapat disimpulkan bahwa keempat variabel tersebut reliabel.

Uji Asumsi Klasik terdiri dari Uji Normalitas, dimana prosedur uji normalitas dilakukan dengan uji kolmogorov smirnov. Jika nilai signifikansi uji Kolmogorov smirnov $>0.05$ (5\%), maka dapat disimpulkan bahwa residual model regresi berdistribusi normal (Ghozali, 2018). Berdasarkan hasil 
uji normalitas di peroleh nilai Asymp Sig (2-tailed) sebesar 0.111. Dapat disimpulkan bahwa data dalam penelitian ini berdistribusi normal, karena hasil tersebut lebih besar dari nilai signifikansi uji kolmogorov-smirnov sebesar 0.05 $(0.111>0.05)$.

Uji Multikolinearitas, Untuk mengetahui ada tidaknya multikolinieritas bisa dilihat dari besaran Variabel Inflation Factor (VIF). Nilai cutoff yang umum digunakan untuk menunjukan adanya multikolonieritas adalah nilai Tolerance $\leq 0,10$ atau sama dengan nilai VIF $\geq 10$ (Ghozali, 2018). Bedasarkan hasil uji multikolinearitas diperoleh nilai tolerance sebesar 0.723, 0,715, 0,829 hasil ini lebih besar dari (>) 0,10. Dan nilai VIF sebesar 1,383 , 1,398, 1,208 hasil ini lebih kecil dari (<) 10. Dapat disimpulkan bahwa Pengaruh Atmosfer Toko, Potongan Harga, Dan Sales Person Terhadap Pembelian Impulsif tidak terjadi gejala multikolinearitas.

Uji Autokorelasi, Untuk menguji ada tidaknya gejala autokorelasidengan menggunakan uji Durbin-Watson (DW test). Adapun kritik pengujiannya adalah $d u<d<4-d u$ maka Ho ditolak yang berarti tidak ada autokorelasi baik positif maupun negative (Ghozali, 2018). Berdasarkan nilai dari tabel Durbin Watson diperoleh nilai $d u$ sebesar 1.736 dan untuk nilai $4-d u$ sebesar 2,264. Diliat dari kritik pengujiannya adalah $d u<d<4-d u(1.736<2.152<2.264)$ maka dapat disimpulkan bahwa tidak ada autokorelasi positif maupun negatif.

Uji Heteroskedastisitas Cara untuk mengetahui ada atau tidaknya heteroskedastisitas adalah dengan melihat grafik plot antara nilai prediksi variabel terikat (dependen variabel) yaitu ZPRED dengan residualnya SRESID. Deteksi ada atau tidaknya heteroskedastisitas dapat dilakukan dengan melihat ada atau tidaknya pola tertentu pada grafik scatterplot antara SRESID dan ZPRED dimana sumbu Y adalah $\mathrm{Y}$ yang telah diprediksi, dan sumbu $X$ adalah residual ( Yprediksi - Y sesungguhnya) (Ghozali,2018).

\section{Hasil Grafik Scatterplot Uji Heterokedastisitas}

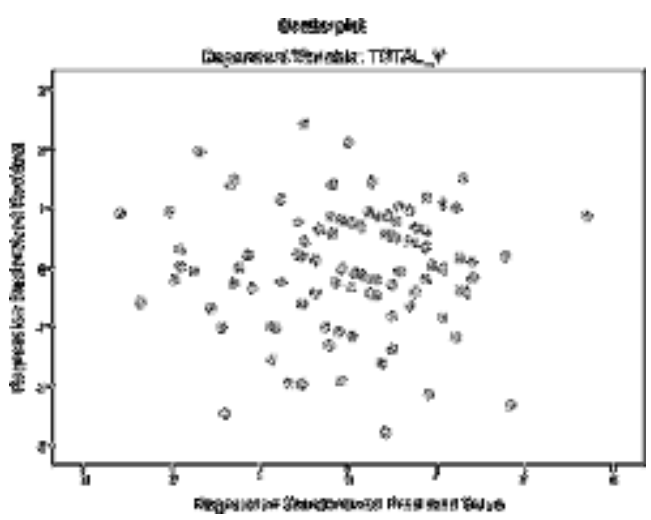

Berdasarkan grafik diatas, terlihat bahwa tidak ada pola yang jelas serta titik-titik tersebut menyebar diatas dan dibawah angka 0 pada sumbu $\mathrm{Y}$. Hal ini menunjukkan bahwa data dalam 
penelitian ini tidak terjadi heterokedastisitas.

Uji Regresi Berganda, Persamaan regresi linear berganda adalah sebagai berikut (Ghozali, 2018):

$\mathrm{Y}=\mathrm{a}+\mathrm{p}_{1} \mathrm{X}_{1}+\mathrm{p}_{2} \mathrm{X}_{2}+\mathrm{p}_{3} \mathrm{X}_{3}+$ eDan Uji t, dengan ketentuan sebagai berikut :.

1. Jika $t_{\text {hitung }}>t_{\text {tabel }}$ maka hipotesisterdukung, maka $\mathrm{H} 0$ ditolak dan Ha diterima, artinya variabel Atmosfer Toko, Potongan Harga, dan Sales Person secara parsial berpengaruh terhadap PembelianImpulsif.
2. Jika $t_{\text {hitung }}<t_{\text {tabel }}$ maka hipotesistidakterdukung, maka Ha ditolak dan H0 diterima, artinya variabel Atmosfer Toko, Potongan Harga dan Sales Person secara parsial tidak berpengaruh terhadap Pembelian Impulsif.

Dengan pengolahannya menggunakan program Statistical Package for Social Science (SPSS) Versi22.

HASIL DAN PEMBAHASAN

Hasil Uji Analisis Regresi Berganda

\begin{tabular}{|c|c|c|c|c|c|}
\hline Hubungan & $\beta$ & $\mathbf{t}_{\text {hitung }}$ & $\mathbf{t}_{\text {tabel }}$ & \multicolumn{2}{|c|}{ Prob. Sig } \\
\hline (Constant) & 2.708 & 0.849 & \multirow[t]{4}{*}{1.660} & 0.398 & \multirow[t]{4}{*}{0.05} \\
\hline $\mathbf{A T}-\mathbf{P I}$ & 0.332 & 2.296 & & 0.024 & \\
\hline $\mathbf{P H}-\mathbf{P I}$ & 0.260 & 1.539 & & 0.127 & \\
\hline $\mathbf{S L}-\mathbf{P I}$ & 0.200 & 1.237 & & 0.219 & \\
\hline
\end{tabular}

Sumber : Data Primer Diolah, Maret 2019.

\section{Hipotesis 1: Atmosfer Toko}

\section{Berpengaruh Positif Terhadap} Pembelian Impulsif

Nilai t hitung pada variabel X1 (AT) sebesar 2.296. Hasil tersebut positif, menunjukkan bahwa semakin baik atmosfer took maka semakin tinggi pembelian impulsif. Untuk nilai t tabel sebesar 1.660. Artinya nilai t hitung lebih besar dari $t$ tabel (2.296 > 1.660). Sedangkan untuk nilai signifikan sebesar 0.024 dengan taraf signifikan sebesar 0.05 $(0.024<0.05)$. Maka hipotesis pertama terdukung atau Ha diterima dan Ho ditolak. Dapat disimpulkan bahwa Atmosfer Toko berpengaruh positif dan signifikan terhadap pembelian impulsif atau dengan kata lain Hipotesis 1 diterima.

Hasil penelitian ini sama dengan hasil peneltian dari Safirah Fakultas Psikologi Universitas 
Muhammadiyah Malang. Dalam penelitiannya disebutkan bahwa Store Atmosphere berpengaruh signifikan dan positif terhadap perilaku Impulse Buying.

\section{Hipotesis 2: Potongan Harga Berpengaruh Positif Terhadap Pembelian Impulsif.}

Nilai t hitung pada variabel X2 $(\mathrm{PH})$ sebesar 1.539. Hasil tersebut positif, menunjukkan bahwa semakin besar potongan harga maka semakin tinggi pembelian impulsif. Untuk nilait tabel sebesar 1.660. Artinya nilai $\mathrm{t}$ hitung lebih kecil dari $\mathrm{t}$ tabel (1.539 > 1.660). Sedangakan untuk nilai signifikan sebesar 0.127 dengan taraf signifikan sebesar 0.05 (0.127 < 0.05). Maka hipotesis kedua tidak terdukung atau Ho diterima dan $\mathrm{Ha}$ ditolak.Dapatdisimpulkan bahwa Potongan Harga tidak berpengaruh terhadap Pembelian Impulsif atau dengan kata lain Hipotesis 2 tidak diterima.

\section{Hipotesis 3: Sales Person Berpengaruh Positif Terhadap Pembelian Impulsif}

Nilai t hitung pada variabel $\mathrm{X} 3$ (SL) sebesar 1.237. Hasil tersebut positif, menunjukkan bahwa semakin baik sales person maka semakin tinggi pembelian impulsif. Untuk nilai t tabel sebesar 1.660. Artinya nilai $\mathrm{t}$ hitung lebih kecil dari $\mathrm{t}$ tabel (1.237>1.660).
Sedangakan untuk nilai signifikan sebesar 0.219 dengan taraf signifikan sebesar $0.05 \quad(0.219<$ 0.05). Maka hipotesis tidak terdukung atau Ho diterima dan $\mathrm{Ha}$ ditolak. Dapat disimpulkan bahwa Sales Person tidak berpengaruh terhadap Pembelian Impulsif atau dengan kata lain Hipotesis 3 tidak diterima.

\section{Pembahasan}

\section{Hubungan Atmosfer Toko}

Terhadap Pembelian Impulsif

Hasil penelitian dari data responden menunjukkan bahwa, perilaku pembelian impulsif mayoritas dilakukan oleh perempuan dengan umur 17 sampai 21 tahun dengan status mahasiswa. Berdasarkan deskriptif variabel Atmosfer toko STB yang terdiri dari tempat parkir dan pencahayaan didalam ruangan toko sudah sangat baik. Selain itu, kondisi ruangan yang nyaman disertai dengan alunan musik yang ada di STB membuat para konsumen nyaman saat berbelanja dan membuat konsumen melakukan pembelian impulsif, disertai dengan pemasangan tanda-tanda produk dan penataan letak produk yang baik memudahkan para konsumen dalam menjangkau produk.

Hasil penelitian ini sejalan dengan penelitian yang disusun oleh Sari dan Suryani, Fakultas Ekonomi dan Bisnis Universitas Udayana (Unud), Bali, Indonesia. Dalam 
penelitiannya disebutkan bahwa atmosfir toko berpengaruh positif signifikan terhadap impulse buying. Selain itu, hasil penelitian oleh Yuniati Safirah Fakultas Psikologi Universitas Muhammadiyah Malang. Dalam penelitiannya juga disebutkan bahwa Store atmosphere berpengaruh signifikan dan positif terhadap perilaku impuls ebuying.

\section{Hubungan Potongan Harga Terhadap Pembelian Impulsif}

Hal ini dikarenakan objek dalam penelitian ini merupakan took ritel yang lebih banyak menyediakan barang kebutuhan, jadi responden tetap akan melakukan pembelian karena merupakan kebutuhan mereka tanpa melihat potongan harga. Selain itu, melihat data responden yang dominan umur 17-21 tahun yang masih berstatus sebagai mahasiswa yang dimana mereka belum memiliki penghasilan tetap sehingga mereka melakukan pembelian impulsif sesuai dengan apa yang mereka butuhkan. Jadi hasil dari variabel potongan harga tidak berpengaruh terhadap variabel pembelian impulsif disebabkan pada objek penelitian, potongan harga yang diberikan selalu pada produk rumah tangga, yang dimana untuk pelajar/mahasiswa mereka jarang membeli produk rumah tangga.

Selain itu, adanya perbedaan persepsi antar responden, dimana berdasarkan jawaban responden dikuesioner, ada responden yang melakukan pembelian impulsif dikarenakan faktor dari potongan harga yang diberikan toko STB, dan ada juga responden yang melakukan pembelian impulsif tidak dikarenakan faktor potongan harga, melainkan responden melakukan pembelian impulsif karena responden membutuhkan produk tersebut.

Hasil ini tidak sejalan dengan penelitian yang dilakukan olehAmsani, dan Hadi pada tahun 2017Administrasi Bisnis, Universitas Diponegoro. Dalam penelitiannya dikatakan Variabel discount (X1) memiliki pengaruh terhadap impulse buying (Y). Dan menurut penelitian yang dilakukan Prihastama (2016), yaitu "harga diskon berpengaruh positif terhadappembelian impulsif'.

\section{Hubungan Sales Person Terhadap Pembelian Impulsif}

Hal ini karena berdasarkan data responden yang diperoleh bahwa $85 \%$ responden yang berstatus sebagai mahasiswa yang dimana mereka memiliki pengetahuan terhadap produk yang akan mereka beli sehingg amereka merasa sales person pada toko STB tidak mereka butuhkan. Kemudian, penyebab lain adalah dari masyarakat Kota Tarakan yang tidak senang/ merasa tidak nyaman /merasa terganggu ketika sales person mendampingi atau memantau konsumen saat berbelanja. Selain itu berdasarkan hasil kuesioner, responden 
cenderung melakukan pembelian impulsif dikarenakan karena responden melihat produk yang terpajang di toko serta karena tidak dapat menahan keinginan mereka saat berada di Toko Sinar Terang Bersaudara.

Hasil ini tidak sejalan dengan penelitian yang dilakukan oleh Tauriana dan Fietrin pada tahun 2011 Jurusan Manajemen, Fakultas Ekonomi dan Bisnis, Universitas Bina Nusantara. Dalam penelitiannya dikatakan bahwa sales person berpengaruh secara signifikan terhadap impulse buying. Dan menurut penelitia yang dilakukan oleh Sri Rahayu Tri Astuti pada tahun 2014 Departemen Manajemen,Fakultas Ekonomika dan Bisnis, Universitas Diponegoro. Dalam penelitian ini disebutkan bahwa Pelayanan Pramuniaga berpengaruh positif terhadap impulse buying.

\section{KESIMPULAN DAN SARAN}

\section{Kesimpulan:}

a. Atmosfer toko berpengaruh positif dan signifikan terhadap pembelian impulsif pada toko Sinar Terang Bersaudara. Artinya, semakin baik atmosfer toko STB, maka semakin tinggi tingkat pembelian impulsif. Jadi, masyarakat Kota Tarakan melakukan pembelian impulsif memang pengaruh dari atmosfer tokotersebut.

b. Potongan harga tidak berpengaruh terhadap pembelian impulsif pada toko Sinar Terang Bersaudara. Artinya, masyarakat Kota Tarakan melakukan pembelian impulsif bukan karena faktor potonganhargayang diberikan toko Sinara Terang Bersaudara. Jadi masyarakat Kota Tarakan tetap akan melakukan pembelianimpulsif meskipun ada atau tidaknya potongan harga yang diberikan toko Sinar Terang Bersaudara.

c. Sales Person tidak berpengaruh terhadap pembelian impulsif pada toko Sinar Terang Bersaudara. Artinya, masyarakat Kota Tarakan melakukan pembelian impulsif bukan karena faktor sales person di toko Sinar Terang Bersaudara. Jadi masyarakat Kota Tarakan tetapakan melakukan pembelian impulsif meskipun ada atau tidaknya sales person pada toko Sinar Terang Bersaudara.

\section{Saran :}

a. Hasil perhitungan variabel atmosfer toko $\left(\mathrm{X}_{1}\right)$, merupakan variabel yang berpengaruh paling tinggi terhadap pembelian impulsif. Untuk itu, perusahaan harus 
mempertahankan atmosfer toko dan memperbaiki kekurangan yang ada, dimana pada indikator ke lima terkait alunan musik pada hasil kuesioner mendapatkan tanggapan paling rendah.

b. Hasil perhitungan variabel potongan

$\operatorname{harga}\left(\mathrm{X}_{2}\right)$,merupakanvariabely ang tidak berpengaruh terhadap pembelian impulsif. Pada pernyataan pertama dalamkuesioner yaitu potongan harga $\mathrm{di} \quad$ STB membuatsayamembeliprodukle bih dari satu mendapatkan tanggapan palingrendah.Untukitu,perusah aan perlu meningkatkan promoberupapotongan harga untukmeningkatkan pembelian impulsif pada toko tersebut

c. Hasil perhitungan variabel sales person $\left(\mathrm{X}_{3}\right)$, merupakan variabel yang tidak berpengaruh terhadap pembelian impulsif. Pada pertanyaan kedua dalam kuesioner yaitu Sales Person (Pramuniaga) di STB memiliki kemampuan dalam menyampaikan informasi produk mendapatkan tanggapan paling rendah. Hal ini, perusahaan perlu memberikan pengarahan dan pelatihan kepada sales person terkait masalah dalam melayani konsumen dan komunikasi

dalammenyampaikan

informasi produk agar dapat mempengaruhi perhatian konsumen untuk melakukan pembelianimpulsif.

d. Penelitian selanjutnyadiharapkandapat memperluas populasi penelitian, yaitu dengan menambah jumlah responden. Selain itu, untuk penyebaran kuesioner diharapkan bisa menyebarkan secara merata keberbagai jenis kalangan usia dan pekerjaan. Selain itu juga, diharapkan penelitian selanjutnya lebih mengevaluasi pertanyaan- pertanyaan yang ada dalam kuesioner agar dapat mewakili secara tepat variabel yang hendak diukur.

e. Penelitian selanjutnya diharapkan dapatmengkajilebihbanyaksum ber maupun referensi terkait dengan atmosfer toko, potongan harga dan sales person terhadap pembelian impulsif agar hasil penelitiannya dapat lebih baiklagi.

f. Mengingat variabel diluar penelitian cukup besar yaitu $81,6 \%$, maka penelitian selanjutnya diharapkan dapat mengembangkan penelitian dengan meneliti variabel lain yang ada diluar penelitian ini atau dengan 
mengkombinasikan variabel yang terdapat dalam penelitian ini dengan variabel lain.

\section{DAFTAR PUSTAKA}

Aini, Q. N., Suharyono, \& Hidayat, K. (2016). Pengaruh Atmosfer Toko Dan Promosi Penjualan Terhadap Shopping Emotion Dan Pembelian Tidak Terencana (Survei terhadap Konsumen Giant Hypermarket Mall Olympic Garden). Jurnal Administrasi Bisnis (JAB), 37(1), 164-170.

Amsani, P. D., \& Hadi, S. P. (2017). Pengaruh discount dan store atmosphere terhadap perilaku impulsive buying (Studi Kasus pada Konsumen Lottemart Wholesale Semarang). Administrasi Bisnis, 6, 4860.

Belch, G. E., Belch, M. A. (2009)

Advertising and Promotion : An IntegratedMarketing Communication Perpective. $8^{\text {th }}$ Edition. New York :McGraw-Hill.

Ben Lowe. (2010). Consumer Perception Of Extra Free Product Promotions and Discount: The Moderating Role of Perceived
Performance Risk. Journal

of Product \& Brand Management. Vol.19, No. 7.

Berman,B. and Evans, JR. (1992). Retail Management. Fifth Edition. USA: Macmillian Publishing Company.

Crawford, G., \& Melewar, T. C. (2003). The importance of impulse purchasing behaviour in the international airport environment. Journal of Consumer Behaviour, 3(1), 85-98.

Foster, Bob. (2008). Manajemen Ritel.Bandung: Alfabeta.

Ghozali, Imam. 2018. Aplikasi Analisis Multivariat Dengan Program IBM SPSS 25, Edisi 9. Semarang: Badan Penerbit Universitas Diponegoro.

Hidayat, Y.N., Astuti,S.R.T. (2017). Analisis Pengaruh Atmosfer Toko, Price Discount Dan Sales Person Terhadap Impulse Buying Melalui Emotional Response (Studi Pada Konsumen Hypermarket Kota Semarang). Volume 6 Nomor 2.

Kotler, Phillip. (2005). Mananjemen Pemasaran, Edisi Kesebelas. Jakarta: PT. Indeks Kelompok Gramedia. 
Kotler, P. \& Amstrong, G. (2001).

Prinsip-Prinsip Pemasaran,

Jilid 2. Edisi ke 8. Jakarta:

Erlangga.

Musyaffaq, D.I. (2017). Pengaruh

Penataan Produk, Atmosfer

Toko, Dan Promosi Below The

Line Terhadap Pembelian

Impulsif Melalui Emosi Positif

Sebagai Variabel Intervening

(Studi Kasus pada Konsumen

Batik Danar Hadi Surakarta).

Fakultas Ekonomi Dan Bisnis

Islam. Institut Agama Islam

Negeri Surakarta.

Nisaq, Z.A. (2017). Analisis

Pengaruh Sikap Pramuniaga,

Profesionalisme Pramuniaga,

Dan Kualitas Produk Terhadap

Kepuasan Konsumen Di

Alfamart Katang Kediri.

Fakultas Ekonomi Universitas Nusantara PGRI Kediri.

Rook, D \& Fisher, J.R. (1995).

Normative Influences On

Impulsive behavior, Journal of

ConsumerResearch.Vol. 22, pp.305-313.

Safirah, Y. Pengaruh Store Atmosphere Terhadap Perilaku Impulsive Buying. Fakultas Psikologi Universitas Muhammadiyah Malang.

Sari, D.A.T, \& Suryani, A. (2008). Pengaruh Merchandising, Promosi Dan Atmosfir Toko Terhadap Impulse Buying, 851-867
Sari, D.U,. (2017). Skripsi Pengaruh Price Discount, Sales Promotion, Dan InStore Display Terhadap Keputusan Impulse Buying Pada Pt Matahari DepartementStore Tbk Panakkukang Makassar. Fakultas Ekonomi dan Bisnis Islam UIN AlauddinMakassar.

Soars, B. (2009). Driving Sales Through Shoppers' Sense Of Sound, Sight, Smell And Touch. International Journal of Retail and Distribution Management, 37(3), 286-298.

Sugiyono, (2017). Metode Penelitian Kuantitatif , Kualitatif dan R\&D. Bandung: Alfabeta, CV.

Sujarweni, W.V. (2015) SPSS untuk penelitian. Yogyakarta: Pustakan Baru Press.

Tauriana, D., \& Fietrin, I. (2011) Pengaruh Penempatan Produk dikasir dan sales person terhadap impulse buying, 12, 61-70

Tendai, M, \& Crispen, C. (2009) In Store Shopping Environment And Impulsive Buying. African Journal of Marketing Management, I (4) $102-108$.

Utami, C.W. (2006), Manajemen Ritel Strategi dan 
Implementasi Ritel Modern,

Jakarta: Salemba Empat.

Wayan Aris Gumilang1 I Ketut

Cahya2. (2016). Pengaruh

Price Discount dan Store

Atmosphere Terhadap

Emotional Shopping dan

Impulse Buying Wayan. E -

Jurnal Manajemen Unud, 15

(3), 1859-1888. 